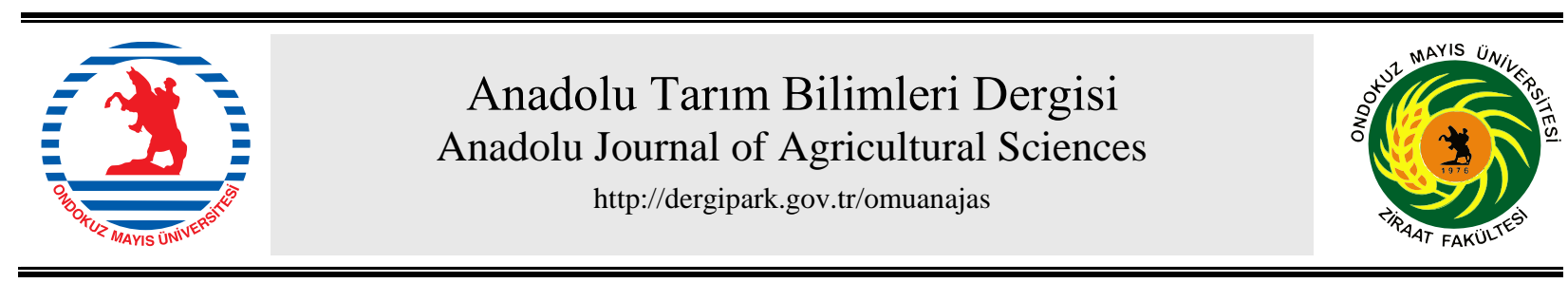

Araştırma/Research

Anadolu Tarım Bilim. Derg./Anadolu J Agr Sci, 36 (2021) ISSN: 1308-8750 (Print) 1308-8769 (Online) doi: 10.7161/omuanajas.869449

\title{
Organomineral ve kimyasal gübre ile farklı fosfor uygulamalarının silaj mısırın verimi ve fosfor kullanım etkinliği üzerine etkileri
}

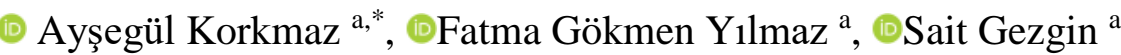 \\ ${ }^{a}$ Selçuk Üniversitesi, Ziraat Fakültesi, Toprak Bilimi ve Bitki Besleme Bölümü, Konya, TÜRKIYE
}

*Sorumlu yazar/corresponding author: aysegul.korkmaz22@gmail.com

Geliş/Received 27/01/2021 Kabul/Accepted 02/05/2021

\begin{abstract}
ÖZET
Bu çalışma, organomineral gübre ve kimyasal gübre ile birlikte K-Humat uygulamalarının silaj mısırın fosfor kullanım etkinliği üzerine etkilerini karşılaştırmak amacıyla tarla koşullarında yürütülmüştür. Tesadüf blokları deneme desenine göre üç tekerrürlü olarak kurulan denemede ekim esnasında $U_{1}$ (\% $100 \mathrm{P})$ kimyasal gübre (13.24.12-10 $\left.\mathrm{SO}_{3}+1 \mathrm{Zn}\right)$, organomineral gübre ile (7.16.10-15 $\mathrm{SO}_{3}+1 \mathrm{Fe}+0.5$ Zn+20 organik madde ) U2 (\% $100 \mathrm{P}$ ) ve azalan oranlarda $\mathrm{U}_{3}(\% 80 \mathrm{P}), \mathrm{U}_{4}$ (\% 60 P), $\mathrm{U}_{5}$ (\% $40 \mathrm{P}$ ) ve kimyasal gübre ile birlikte $6 \mathrm{~L} \mathrm{da}^{-1} \mathrm{~K}$-Humat (\% 12 Humik+fulvik asit) ve kimyasal gübre ile azalan oranlarda $\mathrm{U}_{6}$ (\% 100 P), $\mathrm{U}_{7}$ (\% 80 P), $\mathrm{U}_{8}$ (\% 60 P), $\mathrm{U}_{9}$ (\% 40 P) fosfor uygulanmıştır. Çalışmada, silaj misırın verimi en fazla fosforun \% 80'inin kimyasal gübre ile birlikte dekara 6 L K-Humat uygulaması $\left(\mathrm{U}_{7}\right)$ ile elde edilmiştir. Bitkiye sadece fosforun \% 100 uygulandığı kimyasal gübre yerine K-Humat ile birlikte uygulamasının gerek verimde gerekse fosfor geri alım etkinliğinde artışlara neden olduğu bulunmuştur. Bitkide fosforun geri alım etkinliği gerek organomineral gerekse kimyasal gübre ile birlikte K-Humat uygulamalarının ortalamaları dikkate alındığında, organomineral gübre uygulamasının kimyasal gübre uygulamasına göre \% 2 oranında artış sağladığı belirlenmiştir.
\end{abstract}

\section{Effects of organomineral and chemical fertilizers with K-Humate containing different rates of phosphorus on yield and phosphorus use efficiency of silage corn}

\section{ABSTRACT}

The study was carried out to compare the effects of organomineral fertilizer and chemical fertilizer with K-Humate both containing different rates of phosphorus on the phosphorus use efficiency of silage corn under field conditions. Using randomized completely block design and three replications, chemical fertilizer containing $100 \% \mathrm{P}\left(13.24 .12-10 \mathrm{SO}_{3}+1 \mathrm{Zn}\right) \mathrm{U}_{1}$, organomineral fertilizer $\left(7.16 .10-15 \mathrm{SO}_{3}+1\right.$ $\mathrm{Fe}+0.5 \mathrm{Zn}+20$ organic matter) with $100 \% \mathrm{P}\left(\mathrm{U}_{2},\right), 80 \% \mathrm{P}\left(\mathrm{U}_{3}\right), 60 \% \mathrm{P}\left(\mathrm{U}_{4}\right), 40 \% \mathrm{P}\left(\mathrm{U}_{5}\right)$, and chemical fertilizers with $6 \mathrm{~kg} \mathrm{da}^{-1}$ of K-Humate (12\% Humic + fulvic acid) containing $100 \% \mathrm{P}\left(\mathrm{U}_{6}\right)$, $80 \% \mathrm{P}\left(\mathrm{U}_{7}\right), 60 \% \mathrm{P}\left(\mathrm{U}_{8}\right), 40 \% \mathrm{P}\left(\mathrm{U}_{9}\right)$ were applied. The highest yield was obtained from chemical fertilizer containing $80 \% \mathrm{P}$ and $6 \mathrm{~L} \mathrm{K-Humate} \mathrm{da}^{-1}\left(\mathrm{U}_{7}\right)$. Application of chemical fertilizer containing $100 \% \mathrm{P}$ only is less effective compare to its combination with K-Humat as the latter led to significant increases in yield and phosphorus use efficiency. Based on the phosphorus re-uptake efficiency of the crop, organomineral fertilizer increased yield by $2 \%$ compared to chemical fertilizer with and without K-Humate.
Anahtar Sözcükler: Agronomik etkinlik Fizyolojik etkinlik Geri alım etkinliği K-Humat Organomineral Silaj misır

Keywords: Agronomic efficiency Physiological efficiency Re-uptake efficiency K-Humate Organomineral Silage corn

(C) OMU ANAJAS 2021 


\section{Giriş}

Fosfor bitkiler için mutlak gerekli elementlerden birisidir. Ancak, fosforlu gübreler tarımsal üretimde verimin artırılması için, fosforlu gübre kullanım etkinliğinin az olması nedeniyle uzun yıllardır kontrolsüz ve bilinçsiz bir şekilde fazla miktarlarda kullanılmaktır. Fosfor kullanım etkinliğinin düşük olmasının sebepleri arasında toprağa uygulanan kimyasal fosforlu gübrelerin toprakların yüksek $\mathrm{pH}$, yüksek kireç, kil miktarı ve tipi, az organik madde miktarı, toprak sıcaklığı ve suyu gibi bazı toprak özellikleri yanında gübredeki fosfor formu ve gübrenin uygulama metodu yer almaktadır. Bunlara bağlı olarak değişmekle birlikte gübrelerle uygulanan fosforun fiksasyonunun (\% 50-70) fazla ve bitkilerce alım etkinliğinin (\% 10-30) oldukça düşük olması nedeniyle tarımsal üretimde fosforun kullanım etkinliğin artırılması tarımsal üretimde büyük önem arz etmektedir (Hinsinger, 2001; Balemi ve Negisho, 2012; Cordell ve White, 2013). Gübre kullanım etkinliği agronomik, fizyolojik ve alım etkinliği olmak üzere üç farklı şekilde belirlenmektedir. Agronomik etkinlik, gübre ile uygulanan birim fosforun üründe sağladığı artış; fizyolojik etkinlik, gübre ile uygulanan fosfordan bitkinin aldığ 1 birim fosforun üründe sağladığg artış ve alım etkinliği ise gübre ile uygulanan fosforun bitki ile topraktan kaldırılan oranını ifade etmektedir (Moll ve ark., 1982). Fosforun kullanım etkinliğinin artıılması ile uygulanacak fosforlu gübre miktarının azaltılabilmesi için yapılan çalışmalarda, fosforlu gübre ile birlikte organik kaynaklı materyallerden organomineral gübreler (İrget ve Cengiz; Süzer ve Çulhac1, 2017) ve humik+fulvik asit içerikli K-Humat'ın (El-Etr ve ark., 2011; Tamer ve ark., 2016) verilmesi ile özellikle rizosfer bölgesinde toprakların katyon değişim kapasiteleri, su ve hava geçirgenliği, toprak sıcaklığı üzerine olumlu etkiler sağlayarak mikrobial aktiviteyi artırarak topraklarda fosfor fiksasyonunun azaltılması amaçlanmıştır.

$\mathrm{Bu}$ çalışma, organomineral ve kimyasal gübre ile beraber K-Humat uygulamalarının silaj mısır bitkisi yapraklarının besin elementi kapsamları, tane verimi, kuru madde verimi, fosfor kullanım etkinlikleri ve bu parametreler arasındaki ilişkilerin belirlenmesi amacıyla yapılmıştır.

\section{Materyal ve Yöntem}

Deneme, Tarım İşletmeleri Genel Müdürlüğü Gözlü Tarım İşletmesi arazisinde sulu koşullarda 29 Nisan 2019 tarihinde kurulmuş olup 03 Eylül 2019 tarihinde hasat edilmiştir. Deneme yeri toprağı hafif alkalin reaksiyonlu $(\mathrm{pH}=8.12)$, orta kireçli $(\% 8.1)$, organik maddece fakir $(\% 0.12)$, bitki gelişiminde sorun oluşturamayacak düzeyde tuz $\left(0.61 \mathrm{dS} \mathrm{m}^{-1}\right)$ (Ergene, 1982) içermekte olup killi (C) bünyeye sahiptir. Bitkiye yarayışlı Ca $\left(9686 \mathrm{mg} \mathrm{kg}^{-1}\right)$ ve Mg (1070 mg kg-1) miktarları fazla, K (509 mg kg-1), Fe (7.70 mg kg-1), Zn (1.50 mg kg$)$, Cu (3.60 mg kg $\left.{ }^{-1}\right), \mathrm{Mn}$ (4.06 mg kg-1 ) (Lindsay ve Norvel 1978) ve B $\left(0.45 \mathrm{mg} \mathrm{kg}^{-1}\right)$ miktarları yeterli olan deneme toprağında $\mathrm{NO}_{3}-\mathrm{N}(12.5$ $\mathrm{mg} \mathrm{kg}^{-1}$ ) ve $\mathrm{P}\left(8.99 \mathrm{mg} \mathrm{kg}^{-1}\right.$ ) miktarları silajlık mısır için orta seviyede bulunmaktadır (Ülgen ve Yurtseven 1974).

Tesadüf blokları deneme desenine göre 3 tekerrürlü yürütülen denemede "72 May 80" silajlık mısır çeşidine Çizelge 1'de belirtilen Organomineral, kimyasal gübre, K-Humat ve farklı fosfor içeren 9 adet konu uygulanmıştır.

Deneme yeri toprağının elverişli fosfor $\left(8.99 \mathrm{mg} \mathrm{P} \mathrm{kg}^{-1}\right.$ yani; $\left.5 \mathrm{~kg} \mathrm{P}_{2} \mathrm{O}_{5} \mathrm{da}^{-1}\right)$ miktarına göre Türkiye Gübre ve Gübreleme Rehberi'nde silajlık mısır için önerilen $8 \mathrm{~kg} \mathrm{P}_{2} \mathrm{O}_{5} \mathrm{da}^{-1}$ fosfor optimum yada \% 100 fosfor seviyesi olarak alınmış ve uygulanmıştır. Çizelge 1 'de belirtilen miktarlarda saf fosforu sağlayacak miktarlarda kimyasal ve organomineral gübre, ekim makinesi ile ekim esnasında banda uygulanmıştır. Denemede kimyasal taban gübresi olarak 20-20-0+\% $1 \mathrm{Zn}$ ve organomineral gübre olarak $7.16 .10+\% 15 \mathrm{SO}_{3}+\% 1 \mathrm{Fe}+\% 0.5 \mathrm{Zn}+\% 20$ organik madde içeren kompoze gübre kullanılmıştır. Denemede kullanılan K-Humat'ın pH'sı 11 olup \% 12 hümik+fulvik asit ve $\% 3 \mathrm{~K}_{2} \mathrm{O}$ içermektedir.

Çizelge 1. Uygulama konuları, içerikleri ve miktarları

Table 1. Application parameters, contents and quantities

\begin{tabular}{l|l|c|c}
\hline Uygulamalar & \multicolumn{1}{c|}{ Uygulama İçeriği } & $\begin{array}{c}\text { Uygulanan P Miktarı } \\
\left(\mathbf{k g ~ P}_{\mathbf{2}} \mathbf{O}_{\mathbf{5}} \mathbf{~ d a}^{-\mathbf{1}}\right)\end{array}$ & $\begin{array}{c}\text { Uygulanan K-Humat } \\
\text { Miktarı (L da }^{-\mathbf{1}} \mathbf{)}\end{array}$ \\
\hline $\mathbf{U}_{\mathbf{1}}$ & Kimyasal Gübre (\% 100 P) & 5 & -- \\
$\mathbf{U}_{\mathbf{2}}$ & Organomineral Gübre (\% 100 P) & 5 & - \\
$\mathbf{U}_{\mathbf{3}}$ & Organomineral Gübre (\% 80 P) & 4 & - \\
$\mathbf{U}_{\mathbf{4}}$ & Organomineral Gübre (\% 60 P) & 3 & - \\
$\mathbf{U}_{\mathbf{5}}$ & Organomineral Gübre (\% 40 P) & 2 & - \\
$\mathbf{U}_{\mathbf{6}}$ & Kimyasal Gübre (\% 100 P) & 5 & 6 \\
$\mathbf{U}_{\mathbf{7}}$ & Kimyasal Gübre (\% 80 P) & 4 & 6 \\
$\mathbf{U}_{\mathbf{8}}$ & Kimyasal Gübre (\% 60 P) & 3 & 6 \\
$\mathbf{U}_{\mathbf{9}}$ & Kimyasal Gübre (\% 40 P) & 2 & 6 \\
\hline
\end{tabular}


K-Humat hemen ekim öncesi 6 kat sulandırılıp toprak yüzeyine püskürtülüp toprakla karıştırıldıktan sonra ekim işlemleri yapılmıştır. Denemede bütün uygulama konularında ekim esnasında kompoze gübre ve organomineral gübre ile verilen azot miktarı dikkate alınarak üre gübresi $(\% 46 \mathrm{~N})$ ile silajlı mısırın 6 yapraklı olduğu dönemde 16 $\mathrm{kg} \mathrm{N} \mathrm{da}^{-1}$ ve 12 yapraklı olduğu dönemde de $9 \mathrm{~kg} \mathrm{~N} \mathrm{da}^{-1}$ daha azot verilerek $25 \mathrm{~kg} \mathrm{~N} \mathrm{da}^{-1}$ 'a tamamlanmıştır.

Deneme, 27 parselde yürütülmüş olup, her bir parsel $4.2 \mathrm{~m} \mathrm{x} 200 \mathrm{~m}=840 \mathrm{~m}^{2}$ 'dir. Hasat, parsel başlarından 10'ar $\mathrm{m}$ kenar tesiri bırakılarak $4.2 \mathrm{~m} \times 180 \mathrm{~m}=756 \mathrm{~m}^{2}$ alan biçer-döver ile yapılmıştır. Her parselden ayrı ayrı tartımları yapılarak verimleri kaydedilmiş ve dekara silaj verimleri hesaplanarak belirlenmiştir. Bunun yanında her parselden alınan örnekler $70{ }^{\circ} \mathrm{C}$ 'de sabit ağırlığa gelene kadar kurutularak kuru madde içerikleri belirlenmiş, daha sonra verim $\left(\mathrm{kg} \mathrm{da}^{-1}\right) \mathrm{x}$ kuru madde (\%) / 100 hesabı ile kuru madde verimleri belirlenmiştir. Ayrıca her parselden bitkinin tepe püskülü oluşum döneminde yaprak örnekleri ve hasatta silaj örnekleri alınmıştır. Alınan bu örnekler Selçuk Üniversitesi Ziraat Fakültesi Toprak Bilimi ve Bitki Besleme Bölümü Toprak Gübre ve Bitki Besleme Araştırma Laboratuvarı'nda gerekli ön işlemlerden (yıkama, ön kurutma, öğütme) geçirildikten sonra $70{ }^{\circ} \mathrm{C}^{\prime}$ de hava sirkülasyonlu kurutma dolabında sabit ağırlığa gelinceye kadar kurutulmuştur. Bu örneklerde N LECO C/N analizatöründe Dumas Combustion Metodu'na göre (AACC, 2000) belirlenmiştir. Ayrıca örnekler $\mathrm{HNO}_{3}$ ile mikrodalga sistemde (CEM, MarsXpress ) yaş yakma metoduyla yakılmış ve elde edilen süzüklerde $\mathrm{P}, \mathrm{K}, \mathrm{Ca}, \mathrm{Mg}$, $\mathrm{S}, \mathrm{Fe}, \mathrm{Zn} \mathrm{Cu}, \mathrm{Mn}$ ve B, miktarları ICP-OES (Varian - Vista Model Axial Simultaneous) ile belirlenmiştir.

Organomineral ve kimyasal gübre ile birlikte K-Humat uygulamalarının silaj mısırın fosfor kullanım etkinlikleri (agronomik, fizyolojik ve alım) üzerine etkileri Moll ve ark. (1982) tarafindan bildirilen aşağıdaki formüllerle hesaplanmıştır.

Fosforun agronomik etkinliği $=$ düzeltilmiş tane verimi $\left(\mathrm{kg} \mathrm{da}^{-1}\right) /$ toprakta bulunan ve gübre ile uygulanan $\mathrm{P}_{2} \mathrm{O}_{5}$ $\operatorname{miktar} 1\left(\mathrm{~kg} \mathrm{da}^{-1}\right)$

Fosforun fizyolojik etkinliği $=$ düzeltilmiş tane verimi $\left(\mathrm{kg} \mathrm{da}^{-1}\right) /$ bitkinin aldığ $\mathrm{P}_{2} \mathrm{O}_{5}$ miktarı $\left(\mathrm{kg} \mathrm{da}^{-1}\right)$

Fosforun geri alım etkinliği $=$ bitkinin aldığ $\mathrm{P}_{2} \mathrm{O}_{5}$ miktarı $\left(\mathrm{kg} \mathrm{da}^{-1}\right) /$ toprakta bulunan ve gübre ile uygulanan $\mathrm{P}_{2} \mathrm{O}_{5}$ miktarı $\left(\mathrm{kg} \mathrm{da}^{-1}\right)$

Elde edilen veriler MSTAT-C istatistik paket programı ile tesadüf blokları deneme desenine uygun olarak istatistiki değerlendirmeye tabi tutulmuştur. Her uygulama grubuna ait örneklerin ortalama besin element içerikleri ve fosfor alım etkinlikleri arasındaki farklılıklar varyans analizi yapılmış ve farklılık belirlenen uygulamaların ortalama değerleri "LSD" önem testine göre gruplandırılmıştır. Ayrıca silaj mısırın tepe püskül dönemindeki besin elementleri arasındaki korelasyon analizi JMP 7 istatistik paket programı kullanılarak yapılmıştır.

\section{Bulgular ve Tartışma}

Organomineral ve kimyasal gübre ile birlikte K-Humat uygulamaların silaj mısırın tepe püskül oluşum döneminde alınan yaprakların besin elementi içerikleri Çizelge 2'de verilmiştir. Uygulama konularının tepe püskül oluşum dönemindeki silaj mısır yapraklarının besin element içeriklerine etkisi istatistiki olarak önemsiz bulunmuştur. $\mathrm{Bu}$ döneme ait silaj mısır yapraklarının besin element içerikleri Jones ve ark., (1991) tarafindan

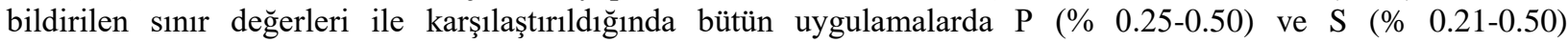
içeriklerinin yetersiz, diğer besin elementlerinin yeterli düzeyde olduğu belirlenmiştir (Çizelge 2). Tepe püskül oluşum döneminde yaprakların fosfor içerikleri, toprağın elverişli fosfor miktarını dikkate alarak silaj mısıra uygulanması gereken fosforun \% 100'ünün verildiği kimyasal gübre uygulaması olan $\mathrm{U}_{1}$ 'e göre fosforun \% 100 'ünün organomineral gübre uygulaması $\left(\mathrm{U}_{2}\right)$ ile \% 11 oranında artmasına rağmen yine de bitkinin fosfor beslenmesine etkili olmadığı belirlenmiştir.

Çizelge 2. Organomineral ve kimyasal ve gübre ile birlikte K-Humat uygulamalarının silaj mısır bitkisinin tepe püskül oluşum döneminde alınan yaprakların makro $\mathrm{P}, \mathrm{K}, \mathrm{Ca}, \mathrm{Mg}$ ve S) ve mikro (Fe, Zn, Cu, Mn ve B) besin elementlerinin içeriklerine etkisi

Table 2. The effect of K-Humat applications Along with organomineral and chemical and fertilizer on the macro $\mathrm{P}, \mathrm{K}, \mathrm{Ca}, \mathrm{Mg}$ and $\mathrm{S})$ and micro (Fe, $\mathrm{Zn}, \mathrm{Cu}, \mathrm{Mn}$ and $\mathrm{B}$ ) nutrient content of the leaves taken during the crown formation period of the silage corn plant 


\begin{tabular}{|c|c|c|c|c|c|c|c|c|c|c|}
\hline \multirow[b]{2}{*}{ Uygulamalar } & $\mathbf{P}$ & $\mathbf{K}$ & Ca & Mg & $\mathrm{S}$ & $\mathbf{F e}$ & Zn & $\mathrm{Cu}$ & Mn & $\mathbf{B}$ \\
\hline & \multicolumn{6}{|c|}{------------- (\%) --------------- } & \multicolumn{4}{|c|}{----------------- mg kg'1-------------- } \\
\hline $\mathbf{U}_{1}$ & $0.18^{*}$ & 1.60 & 0.98 & 0.32 & 0.17 & 152.9 & 42.2 & 20.9 & 100.0 & 32.5 \\
\hline $\mathbf{U}_{2}$ & 0.20 & 1.48 & 0.94 & 0.32 & 0.19 & 156.4 & 42.6 & 19.5 & 92.2 & 32.9 \\
\hline $\mathbf{U}_{3}$ & 0.17 & 1.61 & 0.78 & 0.27 & 0.15 & 157.6 & 34.8 & 16.9 & 76.3 & 26.7 \\
\hline $\mathbf{U}_{4}$ & 0.18 & 1.49 & 0.95 & 0.34 & 0.17 & 163.6 & 42.7 & 19.7 & 81.4 & 30.7 \\
\hline $\mathbf{U}_{5}$ & 0.16 & 1.50 & 0.91 & 0.32 & 0.15 & 163.4 & 43.1 & 18.5 & 108.8 & 31.2 \\
\hline $\mathbf{U}_{6}$ & 0.18 & 1.50 & 0.98 & 0.33 & 0.17 & 161.8 & 39.5 & 19.8 & 112.8 & 29.2 \\
\hline $\mathbf{U}_{7}$ & 0.17 & 1.52 & 0.86 & 0.29 & 0.16 & 146.5 & 35.7 & 20.2 & 88.5 & 24.8 \\
\hline $\mathbf{U}_{8}$ & 0.18 & 1.77 & 0.73 & 0.27 & 0.16 & 141.0 & 34.2 & 18.3 & 72.3 & 24.0 \\
\hline $\mathbf{U}_{9}$ & 0.17 & 1.51 & 0.89 & 0.29 & 0.16 & 151.0 & 37.0 & 18.9 & 91.3 & 26.3 \\
\hline
\end{tabular}

*, Değerler 3 tekerrürün ortalamasıdır.

Tepe püskül oluşum döneminde yaprakların potasyum içerikleri uygulamalara bağlı olarak $\% 1.48$ ile $\% 1.77$ arasında değişmekte olup Jones ve ark. (1991) tarafından bildirilen sınır değerlerine (\% 1.70-3.00) göre fosforun \% 60 '1 ile birlikte dekara 6 L K-Humat uygulanan $\mathrm{U}_{8}$ 'de yeterli, diğer uygulamalarda ise yetersiz (<\% 1.7) düzeydedir.

Silaj mısırın verimi ile tepe püskül oluşum dönemine ait $\mathrm{P}, \mathrm{K}, \mathrm{Ca}, \mathrm{Mg}, \mathrm{S}, \mathrm{Fe}, \mathrm{Zn}, \mathrm{Cu}, \mathrm{Mn}$ ve $\mathrm{B}$ içerikleri arasındaki ilişkiler ve korelasyon katsayıları (r) Çizelge 3'te verilmiştir. Silaj mısır verimi ile yaprakların besin elementleri arasında istatistiki olarak önemli ilişkiler belirlenmemiş̧ir. Yaprakların $\mathrm{P}$ içeriği ile $\mathrm{Ca}, \mathrm{Mg}, \mathrm{S}, \mathrm{Zn}, \mathrm{Cu}$ ve $\mathrm{B}$ içerikleri önemli pozitif ilişkiler belirlenmiştir. Ayrıca silaj mısır yapraklarının $\mathrm{K}, \mathrm{Mg}, \mathrm{Fe}, \mathrm{Zn}$ içerikleri arasında önemli pozitif ilişkiler belirlenmiştir.

Çizelge 3. Organomineral ve kimyasal gübre ile birlikte K-Humat uygulamalarının silaj mısır bitkisinin tepe püskül oluşum döneminde makro (N, P, K, Ca, Mg ve S) ve mikro (Fe, Zn, Cu, Mn ve B) besin element içerikleri ile verim ve kuru madde verim arasındaki ilişkiler ve korelasyon katsayıları ( $\mathrm{r}$ )

Table 3. Relationships and correlation coefficients of the macro (N, P, K, Ca, Mg and S) and micro (Fe, Zn, Cu, $M n$, and $B$ ) nutrient contents of the leaves taken during the crown formation period of the silage corn plant with the yield and dry matter yield after the application of organomineral and chemical fertilizers along with K-Humate

\begin{tabular}{lcccccccccc}
\hline & $\mathbf{P}$ & $\mathbf{K}$ & $\mathbf{C a}$ & $\mathbf{M g}$ & $\mathbf{S}$ & $\mathbf{F e}$ & $\mathbf{Z n}$ & $\mathbf{C u}$ & $\mathbf{M n}$ & $\mathbf{B}$ \\
\hline $\mathbf{K}$ & 0.218 & & & & & & & & & \\
$\mathbf{C a}$ & $0.483^{*}$ & $-0.480^{*}$ & & & & & & & \\
$\mathbf{M g}$ & $0.452^{*}$ & 0.270 & $0.879^{* *}$ & & & & & & \\
$\mathbf{S}$ & $0.740^{* *}$ & 0.124 & $0.718^{* *}$ & $0.635^{* *}$ & & & & & & \\
$\mathbf{F e}$ & 0.368 & 0.213 & $0.584^{* *}$ & $0.656^{* *}$ & 0.276 & & & & & \\
$\mathbf{Z n}$ & $0.608^{* *}$ & 0.326 & $0.896^{* *}$ & $0.869^{* *}$ & $0.760^{* *}$ & $0.575^{* *}$ & & & & \\
$\mathbf{C u}$ & $0.476^{*}$ & 0.025 & $0.589^{* *}$ & $0.417^{*}$ & $0.696^{* *}$ & 0.070 & $0.548^{* *}$ & & & \\
$\mathbf{M n}$ & 0.259 & $0.547^{* *}$ & $0.856^{* *}$ & $0.790^{* *}$ & $0.444^{*}$ & $0.545^{* *}$ & $0.736^{* *}$ & 0.330 & & \\
$\mathbf{B}$ & $0.559^{* *}$ & $0.524^{* *}$ & $0.796^{* *}$ & $0.712^{* *}$ & $0.631^{* *}$ & $0.478^{*}$ & $0.808^{* *}$ & 0.314 & $0.755^{* *}$ & \\
Verim & 0.341 & 0.274 & -0.087 & 0.023 & -0.193 & 0.048 & -0.141 & -0.304 & 0.012 & -0.005 \\
\hline$* *: \mathrm{P}<0.01 ; *: \mathrm{P}<0.05$ & & & & & & & & & &
\end{tabular}

Uygulamalara bağlı olarak değişmekle birlikte silaj mısırın verimi ve kuru madde verimi Şekil 1'de verilmiştir. Bitki verimi en yüksek (6036 kg da-1) fosforun \% 80’inin kimyasal gübre ile birlikte K-Humat uygulaması $\left(\mathrm{U}_{7}\right)$ ile elde edilmiştir. Verim en düşük $\left(5657 \mathrm{~kg} \mathrm{da}^{-1}\right)$ fosforun \% 100 'ünün kimyasal gübre ile verildiği $\mathrm{U}_{1}$ uygulamasında elde edilmiş olup hem fosforun \% 100'ünün organomineral gübre ile uygulaması $\left(\mathrm{U}_{2}\right)$ durumunda hem de kimyasal gübre ile birlikte dekara $6 \mathrm{~L}$ K-Humat uygulaması ile $\left(\mathrm{U}_{6}\right) \% 2$ oranında artış belirlenmiştir. Ayrıca fosforun \% 100 'ünün verildiği $\mathrm{U}_{1}$ uygulamasına göre $\% 80 \mathrm{P}$ kimyasal gübre ile K-humat uygulaması olan $\mathrm{U}_{7} \% 7$, organomineral gübre $\% 40 \mathrm{P}$ verilen $\mathrm{U}_{5}$ uygulaması ile $\%$ 6, \% $40 \mathrm{P}$ kimyasal gübre ile K-humat uygulaması olan $\mathrm{U}_{9}$ $\% 5$, fosforun \% 60'ının verildiği organanomineral $\mathrm{U}_{4}$ ve kimyasal gübre ile K-Humat uygulaması olan $\mathrm{U}_{8} \% 4$ oranlarında artış sağladığı belirlenmiştir. 


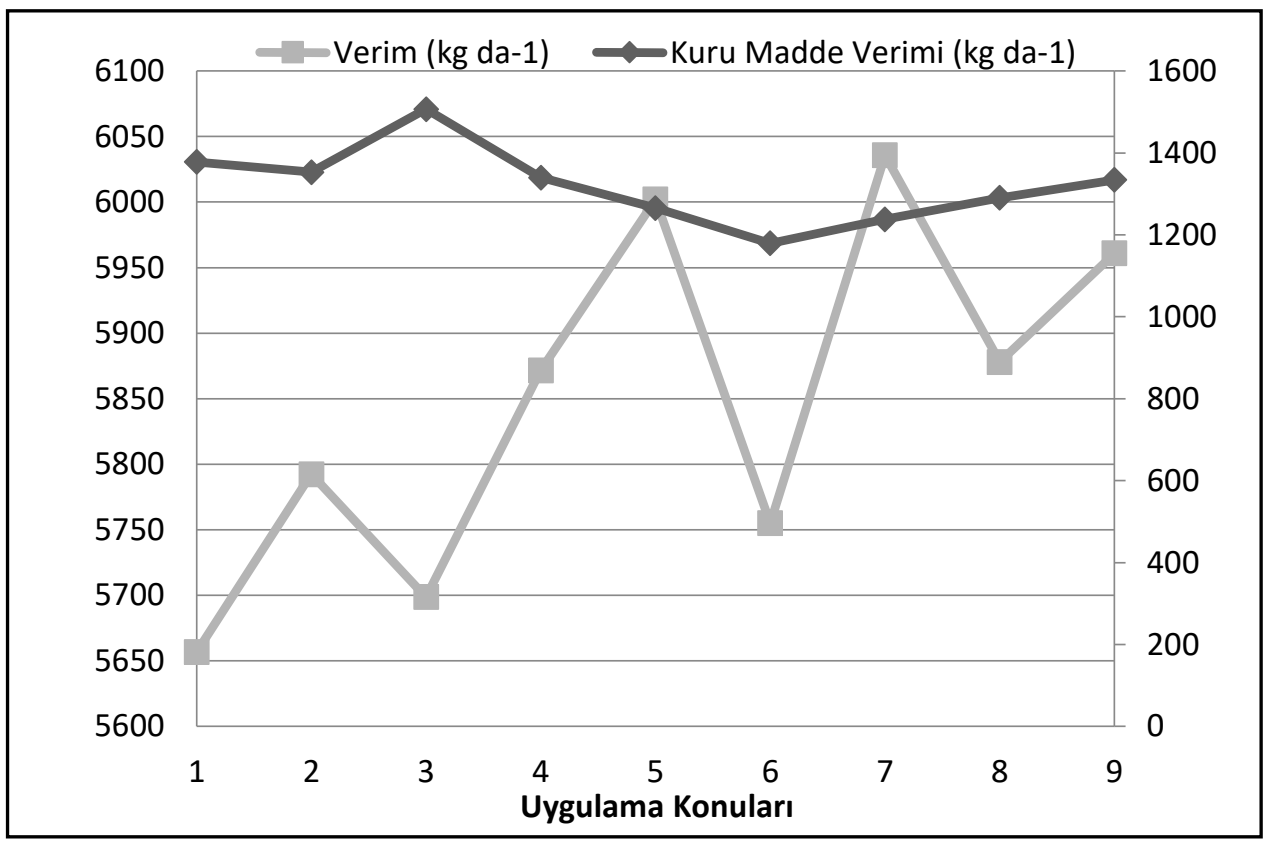

Şekil 1. Organomineral ve kimyasal gübre ile birlikte K-Humat uygulamalarının silaj mısırın verim ve kuru madde verimi üzerine etkisi

Figure 1. The effect of K-Humat applications along with organomineral and chemical fertilizers on yield and dry matter yield of silage corn

Organomineral gübre ile fosfor \% 100'ünün verildiği $U_{2}$ uygulamasına göre $U_{3}$ uygulamasında bir azalış olsa da fosfor oranı azaldıkça silaj veriminde artışlar meydana gelmiştir. Aynı zamanda kimyasal gübre uygulamasına göre organomineral gübre uygulamalarının daha verimli olduğu belirlenmiş olup organik bileşiklerin varlığı toprakta fosforun bağlanmasını azaltmasından ya da engellemesinden kaynaklanıyor olabilir (Gatiboni ve ark., 2003). Organomineral gübre uygulamalarının bitki verimi ve kalitesini arttırdığını bildirmişlerdir (Namlı ve ark., 2019). Mısır üretiminde verim özeliklerinden olan silaj mısırın en yüksek kuru madde verimi organomineral gübre ile fosforun \% 80'inin verildiği $U_{3}$ uygulamasında $\left(1507 \mathrm{~kg} \mathrm{da}^{-1}\right)$, en düşük kuru madde verimi ise kimyasal gübre ile birlikte K-Humat uygulaması olan $\mathrm{U}_{6}$ uygulamasında $\left(1179 \mathrm{~kg} \mathrm{da}^{-1}\right)$ elde edilmiştir. Özata ve ark., (2012) tarafindan farklı silaj mısır çeşitlerinde yapılan çalışmada kuru madde veriminin çalışmamıza benzer şekilde $1104-1815 \mathrm{~kg} \mathrm{da}^{-1}$ arasında değiştiğini belirlemişlerdir.

Uygulamaların silaj mısır kuru madde verimi üzerine etkisi değişmekle birlikte kimyasal gübre ile fosforun \% 100 'ünün verildiği $U_{1}$ uygulamasına göre $U_{3}$ 'de $\% 9$ oranında artış sağlarken diğer uygulamalarda \% 2 ile \% 14 arasında değişen oranlarda azalmalara neden olmuştur. Elde etmiş olduğumuz sonuçlar ile uyumlu olarak farklı bitkilere organomineral gübre uygulaması ile kuru madde verimde artış sağlandığını belirtmişlerdir (Olaniyi ve Ojetayo, 2010; Makinde ve ark., 2011; Süzer ve Çulhacı, 2017). Fosforun \% 100'ünün uygulandığı kimyasal gübre ile birlikte dekara $6 \mathrm{~L}$ K-Humat uygulamasına göre $\left(\mathrm{U}_{6}\right)$ fosforun azalan oranlarda uygulandığı uygulamalarda bitki kuru madde veriminin \% $5\left(\mathrm{U}_{7}\right)$ ile \% $13\left(\mathrm{U}_{9}\right)$ arasında değişen oranlarda arttığı belirlenmiştir. Birçok çalışmada mısır bitkisine K-Humat uygulamalarının silaj verimi ve kuru madde verimini artırması, kök bölgesinde besin elementlerinin elverişliliğinin artması ve büyümeyi teşvik edici maddelerin etkisiyle kök sisteminin daha iyi gelişmesi sonucu toprak suyundan ve besin elementlerinden daha iyi faydalanmasi ve dengeli beslenmesinden kaynaklanarak verimi artırdığı bildirilmektedir (Wang ve ark., 1995; Bozoğlu ve ark., 2004; Erdal ve ark., 2014).

Çizelge 4. Kimyasal ve organomineral gübre ve K-Humat konularının tane mısır bitkilerinin P içeriği, agronomik etkinliği, fizyolojik etkinliği ve fosfor alım etkinliği üzerine etkileri

Table 4. Effects of chemical and organomineral fertilizer and K-Humat on the P content, Agronomic activity, physiological activity and phosphorus uptake efficiency of corn crops

\begin{tabular}{|c|c|c|c|c|c|c|c|}
\hline \multirow{3}{*}{ Uygulamalar } & \multirow{3}{*}{$\begin{array}{c}\text { Silaj İle } \\
\text { Kaldırılan } \\
\mathbf{P}_{2} \mathbf{O}_{5} \\
\text { İçeriği }\end{array}$} & \multirow{3}{*}{$\begin{array}{c}\text { Toprakta } \\
\text { Mevcut } \\
\mathbf{P}_{2} \mathbf{O}_{5} \\
\text { Miktarı }\end{array}$} & \multirow{3}{*}{$\begin{array}{c}\text { Gübre İle } \\
\text { Verilen } \\
\mathrm{P}_{2} \mathrm{O}_{5} \\
\text { Miktarı }\end{array}$} & \multirow{3}{*}{$\begin{array}{c}\text { Toplam } \\
\text { (Toprak+ } \\
\text { Gübre } \mathbf{P}_{2} \mathrm{O}_{5} \\
\text { Miktarı ) }\end{array}$} & \multicolumn{3}{|c|}{ Gübre Kullanım Etkinliği } \\
\hline & & & & & \multicolumn{3}{|c|}{ Fosfor } \\
\hline & & & & & $\begin{array}{c}\text { Agronomik } \\
\text { Etkinlik }\end{array}$ & $\begin{array}{c}\text { Fizyolojik } \\
\text { Etkinlik }\end{array}$ & $\begin{array}{l}\text { Geri } \\
\text { Alım }\end{array}$ \\
\hline
\end{tabular}




\begin{tabular}{|c|c|c|c|c|c|c|c|}
\hline & & & & & $\left(\mathrm{kg} \mathrm{kg}^{-1}\right)$ & $\left(\mathrm{kg} \mathrm{kg}^{-1}\right)$ & $\begin{array}{c}\text { Etkinliği } \\
(\%)\end{array}$ \\
\hline $\mathbf{U}_{1}$ & $5.65 \mathrm{CD}$ & 5 & 8.0 & 13.0 & $106 \mathrm{D}$ & $246 \mathrm{C}$ & $43 \mathrm{D}$ \\
\hline $\mathbf{U}_{2}$ & $6.05 \mathrm{~A}$ & 5 & 8.0 & 13.0 & $104 \mathrm{D}$ & $226 \mathrm{D}$ & 47 CD \\
\hline $\mathbf{U}_{3}$ & $5.37 \mathrm{E}$ & 5 & 6.4 & 11.4 & $132 \mathrm{C}$ & $283 \mathrm{~A}$ & 47 CD \\
\hline $\mathbf{U}_{4}$ & $5.75 \mathrm{BC}$ & 5 & 4.8 & 9.8 & 137 BC & $235 \mathrm{D}$ & 59 B \\
\hline $\mathbf{U}_{5}$ & $5.50 \mathrm{DE}$ & 5 & 3.2 & 8.2 & $154 \mathrm{AB}$ & $201 \mathrm{~F}$ & $67 \mathrm{~A}$ \\
\hline $\mathbf{U}_{6}$ & $5.50 \mathrm{DE}$ & 5 & 8.0 & 13.0 & $91 \mathrm{D}$ & $215 \mathrm{E}$ & $42 \mathrm{D}$ \\
\hline $\mathbf{U}_{7}$ & $5.78 \mathrm{BC}$ & 5 & 6.4 & 11.4 & $109 \mathrm{D}$ & $214 \mathrm{E}$ & $51 \mathrm{C}$ \\
\hline $\mathbf{U}_{8}$ & $5.01 \mathrm{~F}$ & 5 & 4.8 & 9.8 & $132 \mathrm{C}$ & $260 \mathrm{~B}$ & $51 \mathrm{C}$ \\
\hline $\mathbf{U}_{9}$ & 5.84 B & 5 & 3.2 & 8.2 & $163 \mathrm{~A}$ & $229 \mathrm{D}$ & $71 \mathrm{~A}$ \\
\hline
\end{tabular}

*, Değerler 3 tekerrürün ortalamasıdır. A, B: $\mathrm{P}<0.01 ; \mathrm{a}, \mathrm{b}: \mathrm{P}<0.05$

Silaj mısırın fosfor kullanım etkinlikleri uygulama konularına bağlı olarak değişmekle birlikte, fosforun agronomik etkinliğinin $91\left(U_{6}\right)$ ile $163\left(U_{9}\right) \mathrm{kg} \mathrm{kg}^{-1}$, fizyolojik etkinliğinin $201\left(U_{5}\right)$ ile $283\left(U_{3}\right) \mathrm{kg} \mathrm{kg}^{-1}$ ve geri alım etkinliğinin ise \% $43\left(U_{1}\right)$ ile \% $71\left(U_{9}\right)$ arasında değiștiği belirlenmiştir (Çizelge 4). Farklı gübre uygulamalarına göre fosforun agronomik, fizyolojik ve geri alım etkinliğindeki değişimler istatistiki olarak $\mathrm{P}<0.05$ düzeyinde önemli bulunmuştur. Silajlık mısırın fosfor agronomik etkinliği diğer bir ifade ile toprakta bulunan toplam (toprak+gübre) fosforun bir birimi ile oluşan verimi, bitkiye verilmesi gereken fosforun \% 100 'ünün kimyasal gübre ile verildiği $U_{1}$ uygulamasına göre büyükten küçüğe doğru $U_{9}>U_{5}>U_{4}>U_{3}=U_{8}>U_{7}>U_{2}>U_{6}$ şeklinde sıralanmıştır. Organomineral gübre $\left(\mathrm{U}_{2}\right)$ ve kimyasal gübre ile birlikte K-Humat $\left(\mathrm{U}_{6}\right)$ uygulamaları ile sırasıyla $\% 2$ ve $\% 14$ oranında azalmalara neden olmuştur.

Mısırın fosfor agronomik etkinliği sadece fosforun kimyasal gübre ile verilmesine göre kimyasal gübre ile birlikte K-Humat uygulamalarının daha etkili olduğu belirlenmiştir. Ayrıca organomineral gübre ile fosforun azalan dozlarda uygulanması ile bitki agronomik etkinliğin artış gösterdiği bulunmuştur. Bitkide fosforun agronomik etkinliği genel olarak hem organomineral gübre de hem de kimyasal gübre ile birlikte K-Humat uygulamalarında fosfor uygulamasının artışına bağlı olarak azalmalar belirlenmiştir.

Gomes ve ark. (2018) bulgularımıza benzer şekilde, fosfor agronomik etkinliğinin mısır çeşitlerine ve uygulanan fosfor dozuna bağlı olarak değiştiğini, uygulanan fosfor miktarının artışı ile fosfor agronomik etkinliğinin azaldığını bildirmişlerdir.

Bitkide fosfor fizyolojik etkinliği üzerine etkileri $U_{1}$ uygulamasına göre organomineral gübre ile fosforun \% 60'ının uygulandığı $\mathrm{U}_{4}$ uygulaması ile $\%$ 8, fosforun \% 40'ının uygulandığı $\mathrm{U}_{5}$ uygulamas 1 ile \% 18 oranlarında azalmalar belirlenmiş olup diğer uygulamalardaki $\left(U_{4}, U_{6}, U_{7}\right.$ ve $\left.U_{9}\right)$ azalmalar ise bu oranlar arasında değişmektedir. Bitki tarafından alınan bir birim fosforun verime yansıması olarak incelenen bitki fosforunun fizyolojik etkinliği en fazla organomineral gübre ile fosforun \% 80'inin uygulandığ $\mathrm{U}_{3}$ uygulaması ile elde edilmiş olup bunu fosforun \% 60'inin kimyasal gübre ile birlikte K-Humat'in birlikte uygulandığ $\mathrm{U}_{8}$ uygulaması ile belirlenmiştir. Parentoni ve Souza Júnior (2008), 28 farklı mısır çeşidinde fosforun fizyolojik etkinliğinin uygulamalara bağlı olarak değiştiğini yüksek fosfor uygulaması ile etkinliğin azaldığını bildirmişlerdir. Silajlık mısırın fosfor geri alım etkinliği diğer bir ifade ile toprakta bulunan toplam (toprak+gübre) fosforun bir biriminin bitkilerce alınan fosfor miktarı, büyükten küçüğe doğru $U_{9}>U_{5}>U_{4}>U_{7}=U_{8}>U_{2}=U_{3}>U_{1}>U_{6}$ şeklinde sıralanmıştır. Bitki fosforunun geri alım etkinliği uygulamalara bağlı olarak değişmekle birlikte \% $9\left(U_{2}\right.$ ve $\left.U_{3}\right)$ ile \% $65\left(U_{9}\right)$ arasında değişen oranlarda artmıştır. Fosforun geri alım etkinliği bitkiye kimyasal gübre ile birlikte dekara $5 \mathrm{~kg} \mathrm{P}_{2} \mathrm{O}_{5}$ uygulamasında \% 43 iken aynı miktarda fosforun organomineral gübre ile uygulamasıyla \% 9 artarken, aynı fosfor miktarının K-Humat ile birlikte kimyasal gübre ile uygulanmasıyla \% 2 oranında azalmaların olduğu belirlenmiştir. Fosfor geri alım etkinliği en yüksek $U_{5}$ ve $U_{9}$ uygulamaları ile elde edilmiş olup bu uygulamalar arasında istatistiki bakımdan fark bulunmamıştır. Ayrıca bitki fosforunun geri alım etkinliği uygulanan fosfor miktarının azalmasına bağlı olarak artmıştır. Benzer çalışmalarda da fosfor alım etkinliğinin, fosfor dozlarının azalması (Fernández ve ark., 2009; Singh ve Singh, 2016) ve kimyasal, organik gübre uygulamaları (Makinde ve ark., 2011; Poblete-Grant ve ark., 2019) ile arttığını bildirmişlerdir.

\section{Sonuç}

Çalışma sonucunda, silaj mısır bitkisinin verimi ve fosfor kullanım etkinliği uygulamalara bağlı olarak değişmekle birlikte organomineral gübreyle uygulanan fosfor miktarının azalışı ile verimde ve geri alım etkinliğinde artışlar belirlenmiştir. Bitkiye sadece fosforun \% 100 uygulandığı kimyasal gübre yerine K- Humat ile birlikte uygulamasının gerek verimde gerekse fosfor geri alım etkinliğinde artışlara neden olduğu bulunmuştur. Bitkide 
fosforun geri alım etkinliği gerek organomineral gerekse kimyasal gübre ile birlikte K-Humat uygulamalarının ortalamaları dikkate alındığında, organomineral gübre uygulamasının (\% 55) kimyasal gübre uygulamasına (\% 54) göre \% 2 oranında artış sağladığı belirlenmiştir. Yüksek pH'lı düşük organik madde ve fosfor içerikli topraklarda organik materyal içerikli organomineral gübrelerin kullanımı ile toprak fosforunun elverişliliğinin artmasıyla fosfor alım etkinliğinin az da olsa artırılması sağlandığı için organomineral gübrelerin kullanımının bitki gelişiminde daha etkili olduğu belirlenmiştir.

\section{Teşekkür}

Ülkemizde, organomineral gübrelerin bitki gelişimi ve beslenmesine etkisi ile ilgili bilgi eksikliğinin giderilmesine katkı sağlamak için bu çalışmanın yürütülmesini sağlayan Tarım İşletmeleri Genel Müdürlüğüne (TİGEM), aynı kurumun Bitkisel Üretim Daire Başkalığına, Gözlü İşletmesi’nde emeği geçenlere çok teşekkür ediyoruz.

\section{Kaynaklar}

AACC, 2000. Approved Methods of the AACC, Methods.

Balemi, T. ve Negisho, K., 2012. Management of soil phosphorus and plant adaptation mechanisms to phosphorus stress for sustainable crop production: a review. Journal of Soil Science and Plant Nutrition, 12 (3), 547-562. doi.org/10.4067/S0718-95162012005000015.

Bozoğlu, H., Pekşen, E. ve Gülümser, A., 2004. Sıra aralığı ve potasyum humat uygulamasının bezelyenin verim ve bazı özelliklerine etkisi. Doi: 10.15832/ankutbd.577277.

Cordell, D. ve White, S., 2013. Sustainable phosphorus measures: strategies and technologies for achieving phosphorus security. Agronomy, 3 (1), 86-116. doi.org/10.3390/agronomy3010086.

El-Etr, W. T., Osman, M. A. ve Mahmoud, A., 2011. Improving Phosphorus Use Effeciency And Its Effect On The Productivity Ductivity Of Some Crops. Journal of Soil Sciences and Agricultural Engineering, 2 (9), 1019-1034. doi: 10.21608/JSSAE.2011.55708.

Erdal, İ., Küçükyumuk, Z., Taplamacıoğlu, D. ve Toftar, B., 2014, Kireçli bir toprakta humik ve fulvik asit uygulamalarının domatesin gelişimi ve beslenmesine etkileri, Toprak Bilimi ve Bitki Besleme Dergisi, 2 (2), 70-74.

Ergene, A., 1982. Toprak bilgisi, Atatürk Üniversitesi Ziraat Fakültesi Yayınları (267).

Fernández, M., Belinque, H., Boem, F. G. ve Rubio, G., 2009. Compared phosphorus efficiency in soybean, sunflower and maize, Journal of Plant Nutrition. 32 (12), 2027-2043. doi.org/10.1080/01904160903308135.

Gatiboni, L., Kaminski, J., Rheinheimer, D. ve Brunetto, G., 2003. Superphosphate and Rock Phosphates as Phosphorus Sources for Grass-Clover Pasture on a Limed Acid Soil in Southern Brazil, Communications in soil science and plant analysis. 34 (17-18), 2503-2514. doi.org/10.1081/CSS-120024782.

Gomes, E. A., Lana, U. G., Quensen, J. F., de Sousa, S. M., Oliveira, C. A., Guo, J., Guimarães, L. J. ve Tiedje, J. M., 2018. Root-associated microbiome of maize genotypes with contrasting phosphorus use efficiency, Phytobiomes, 2 (3), 129-137. doi.org/10.1094/PBIOMES-03-18-0012-R.

Hinsinger, P., 2001. Bioavailability of soil inorganic P in the rhizosphere as affected by root-induced chemical changes: a review. Plant and Soil, 237 (2), 173-195.

İrget, M. E. ve Cengiz, A., 2017. Organik Maddenin Toprak Kalitesi ve Üretime Etkileri, Çalıştay Bildiriler, 17.

Jones, J. B., Wolf, B. ve Mills, H. A., 1991. Plant analysis handbook. Micro, Macro Publishing, Inc., Athens, GA.

Lindsay, W. L. ve Norvell, W. A., 1978. Development of a DTPA soil test for zinc, iron, manganese, and copper. Soil Science Society of America Journal, 42 (3), 421-428. doi.org/10.2136/sssaj1978.03615995004200030009x.

Makinde, E., Ayeni, L. ve Ojeniyi, S., 2011. Effects of organic, organomineral and NPK fertilizer treatments on the nutrient uptake of Amaranthus cruentus (L) on Two Soil Types in Lagos. Nigeria, Journal of Central European Agriculture, 12 (1), 114-123.

Moll, R., Kamprath, E. ve Jackson, W., 1982. Analysis and interpretation of factors which contribute to efficiency of nitrogen utilization ${ }^{1}$. Agronomy journal, 74 (3), 562-564. doi.org/10.2134/agronj1982.00021962007400030037x.

Namlı, A., Akça, M. O. ve Hanife, A., 2019. Afşin-Elbistan havzası linyit işletmesi organik materyallerinden geliştirilen organik ve organomineral gübrelerin buğday verimi ve verim bileşenleri ile bazı toprak özellikleri üzerine etkileri. Toprak Bilimi ve Bitki Besleme Dergisi, 7 (1), 10-20. Doi: 10.33409/tbbbd.594998.

Olaniyi, J. ve Ojetayo, A., 2010. The effect of organomineral and inorganic fertilizers on the growth, fruit yield and quality of pepper (Capsicum frutescence). Journal of Animal and Plant Sciences (JAPS), 8 (3), 1070-1076.

Parentoni, S. N. ve Souza Júnior, C. L. d., 2008. Phosphorus acquisition and internal utilization efficiency in tropical maize genotypes. Pesquisa Agropecuária Brasileira, 43 (7), 893-901. doi.org/10.1590/S0100-204X2008000700014. 
Poblete-Grant, P., Biron, P., Bariac, T., Cartes, P., Mora, M. d. L. L. ve Rumpel, C., 2019. Synergistic and antagonistic effects of poultry manure and phosphate rock on soil P availability, ryegrass production, and P Uptake. Agronomy, 9 (4), 191. doi.org/10.3390/agronomy9040191.

Singh, N. ve Singh, G., 2016. Response of lentil (Lens culinaris Medikus) to phosphorus-A review. Agricultural Reviews, 37 (1), 27-34. doi: 10.18805/ar.v37i1.9261.

Süzer, S. ve Çulhacı, E., 2017. Farklı organomineral ve inorganik kompoze gübrelerin kışlık ekmeklik buğday tane verimi ve bazı verim unsurları üzerine etkileri. Toprak Bilimi ve Bitki Besleme Dergisi, 5 (2), 87-92.

Tamer, N., Başalma, D., Türkmen, C. ve Namlı, A., 2016. Organik toprak düzenleyicilerin toprak parametreleri ve ayçiçeği (Helianthus annuus L.) bitkisinin verim ve verim öğeleri üzerine etkileri. Toprak Bilimi ve Bitki Besleme Dergisi, 4 (1), 11-20.

Ülgen, N., Yurtsever, N., 1974. Türkiye Gübre ve Gübreleme Rehberi. Köyişleri ve Kooperatifler Bakanlığı, Toprak Gübre Araşt. Enst. Yay., No: 28, Ankara.

Wang, X., Wang, Z. ve Li, S., 1995. The effect of humic acids on the availability of phosphorus fertilizers in alkaline soils. Soil use and management, 11 (2), 99-102. doi.org/10.1111/j.1475-2743.1995.tb00504.x. 